\title{
Consanguineous marriages profile in the Tanger-Tetouan region in Morocco
}

\author{
H. Hardouz ${ }^{1}$, H. Hami ${ }^{1}$, A. Mokhtari ${ }^{1}$, A. Soulaymani ${ }^{1}$, L. Sbai ${ }^{1}$, \\ S. El kheddam ${ }^{1}$, Z. Doukkali ${ }^{2}$, A. Quyou ${ }^{1}$ \\ ${ }^{1}$ Laboratory of Genetics and Biometry, Faculty of Science, IbnTofail University, Kenitra, Morocco \\ ${ }^{2}$ Laboratoire de Pharmacologie et Toxicologie, Faculté de médecine et de pharmacie, Université Mohammed \\ V.Maroc
}

\begin{abstract}
Consanguineous marriage has received a great deal of attention as a potential risk factor for many adverse health outcomes. More than a billion people in the world live in regions where 20\%-50\% of marriages are consanguineous. The aim of this study is to determine the frequency and types of consanguineous marriage in the region of Tanger-Tetouan in Northwest Morocco. Methods: A prospective study was conducted among a randomly selected sample of 160 university students in Tanger in 2014. All students were interviewed using a structured questionnaire. Results: The frequency of consanguineous marriages among parents of students was $39,4 \%$, with a mean inbreeding coefficient (up to second cousins) of 0,02033. The study revealed a highly significant difference in the rates of the consanguineous marriages between the current and previous generation $p<0,001$. The most common types of consanguineous marriage among current generationwere first cousin marriage, which accounts for $76,2 \%$ of all consanguineous unions, followed by first cousin once removed $(11,1 \%)$ and second cousin marriage $(3,2 \%)$, while 9,5\% of marriages were between distant relatives. Among the previous generation, more than half of consanguineous marriages were between first cousins, whereas more the $40 \%$ of unions were of distant relatives. The distribution of the marriages between first cousins through the generations showed that the frequency of unions between parallel cousins was superior than that of the unions between crossed cousins. It was 60, $42 \%$ against 39, 58 \% respectively to the current generation. Among the parallel first cousins, the marriage with the daughter of brother of the father was the most answered that with the daughter of sister of mother to both studied generations. The rate was 68, $97 \%$ against 31, $03 \%$ to the generation of the parents, then, it was $85,71 \%$ against $14,29 \%$ and $83,33 \%$ against $5,88 \%$ to the generation of the paternal and maternal parents, respectively. Conclusion: Consanguineous marriage plays an important role in expression of deleterious recessive genes. Public awareness of genetic risks associated with consanguineous marriage and the importance of premarital genetic counseling is indispensable.
\end{abstract}

Key Words: Consanguineous marriage Coefficient inbreeding Typesconsanguinity Morocco

\section{Introduction}

The consanguineous marriage is defined as being the union between individuals possessing one or several common ancestors. It is a practice still respected in the majority of the communities of North Africa, the Middle East and western Asia [1].Approximately 1 billion people live at present in countries where the consanguineous marriages are the rule and among them a person out of three of the marriages is between cousins [2].This marriage type is very answered in the countries of the Maghreb in spite of the modernization [3]. Moreover, a survey on the Population and the Health in Morocco denoted that the rate of consanguinity was $33 \%$ [4] in 1987 and $29 \%$ in 2011[5].Also, studies made in certain regions of Morocco still showed the dominance of this practice, in particular between the first cousins with frequencies varying relatively from a region to another. Numerous factors enter the choice of this marriage type, in particular the geographical closeness [6], the socioeconomic level also plays an important role in this type of union. In spite of these advantages which could motivate this type of union, the consanguineous marriage is not only involved in the incidence of the hereditary diseases recessive autosomal, but also in the growth of the multifactorial diseases [7]. The objective of our study is to determine the frequency of the consanguineous marriage, the coefficient of inbreeding and types of consanguineous unions in the sample in the region of Tanger-Tetouan Morocco.

\subsection{Area of study}

\section{Patients And Methods}

The region of Tanger-Tetouan is situated extremely in Northwest of Morocco. It is limited to the North by the Strait of Gibraltar and the Mediterranean Sea, on the West by the Atlantic Ocean, in the South by the region of Gharb-Chrarda-BéniHssen and in the East by the region of Taza-Al Hoceima-Taounate. Unlike all other regions of Morocco, the region of wilayas Tanger-Tetouan accounts two Wilaya: the first one of Tanger 
and second of Tetouan, The region of Tanger-Tetouan counts the provinces of Chefchaouen, FahsAnjra, Larache, Ouezzane, Tetouan and the prefectures de Tanger-Assilah and Mdiq-Fnidek. His surface is 12, 425 $\mathrm{km}^{2}$. The population is estimated in 2011 to 2668000 inhabitants without considered the province of Ouezzane(Figure1)[8].

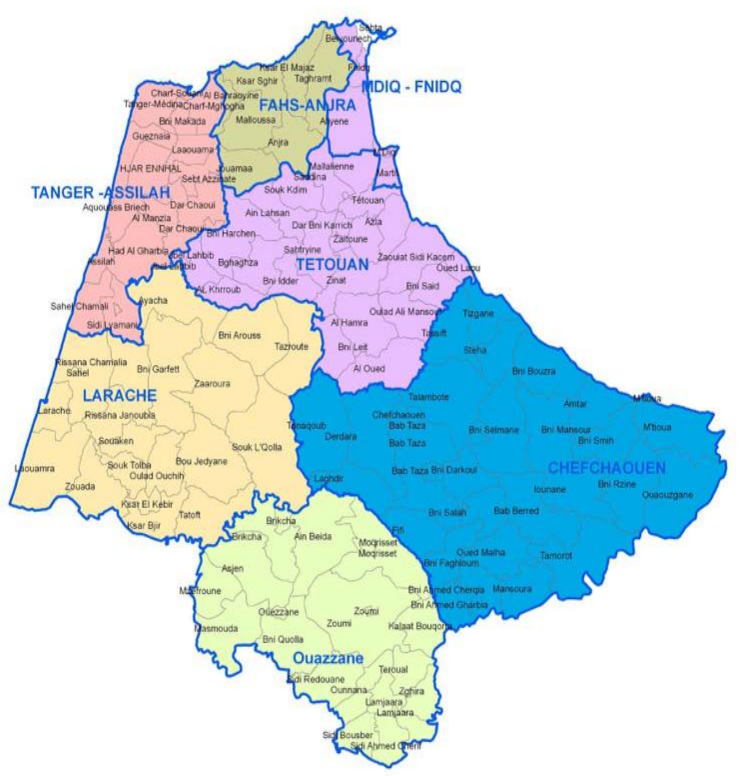

Fig.1.The Geographical position of the region of Tanger-Tetouan within Morocco

\subsection{Source of information}

The data collection which is used in this study was a questionnaire developed by the team of Laboratory of Genetic and Giometry of Faculty of science in Kenitra, intended for the students. This questionnaire, besides the respect for the ethics for the questioned, contained data relative to the characteristics of the consanguinity of the parents of every student before and after their marriage as «current Generation" and on their paternal and maternal grandparents "previous Generation".

\subsection{Studied parameters}

The studied characters concerned the rate of the consanguineous marriages, the types of consanguineousmarriage and the coefficient of consanguinity to the population of the region of Tanger-Tetouan of Morocco.

\subsubsection{Type of the consanguineous marriage and Coefficient of consanguinity}

The geneticists classify the consanguineous marriages according to the Coefficient of consanguinity. Coefficient of consanguinity of an individual I (FI), is the probability that two equivalent genes are identical by mendelienne descent (Inherited from the same common ancestor) [9].

If the parents are not related: $\mathrm{F}=0$

In other cases FI is calculated according to the degrees of relationship between the individual and one or several common ancestors.

$$
\mathrm{FI}=\sum \underset{\substack{\mathrm{n} \\ \mathrm{I}=1}}{(1 / 2) \mathrm{m}+\mathrm{p}+1}
$$

$\mathrm{M}=$ The number of generations which connect the mother of I to the common ancestor.

$\mathrm{P}=$ The number of generations which connect the father of I to the common ancestor.

$\mathrm{n}=$ Number of common ancestors.

For example, in a first cousin marriage, the FI value for offspring is $0,0625(1 / 16)$. For double first cousins, FI value of $0,125 \%$ (1/8). As for first cousins once removed and second cousins, value FI is $1 / 32$ and $1 / 64$ respectively (Figure 2 ).

First cousin type was then divided into four subtypes: patrilateral parallel first cousin (Type I or Father's Brother's Daughter), matrilateral parallel first cousin (Type II or Mother's Sister's 
Daughter).Patrilateral cross first cousin (Types III or Father's Sister's Daughter), and matrilateral cross first cousin (Types IV or Mother's Brother's Daughter) (Figure 3).

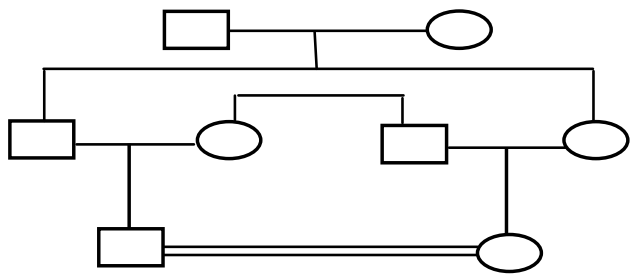

Double First Cousins

$$
F_{l}=1 / 8
$$

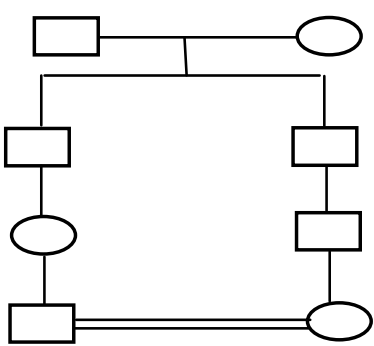

Second Cousins

$F_{l}=1 / 64$

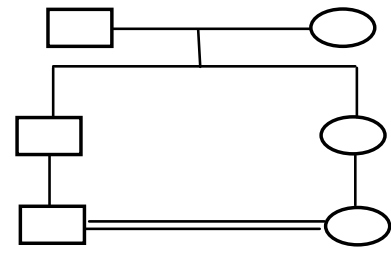

First Cousins

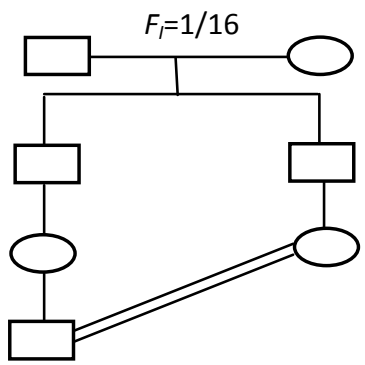

First Cousins Once Removed

$F_{l}=1 / 32$

Fig.2. Types of Consanguineous Marriages and Coefficient of Inbreeding of Descendants

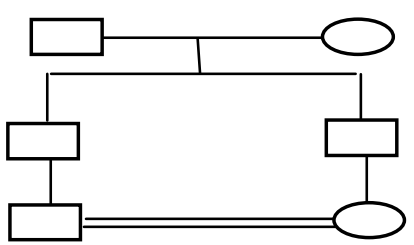

Type I(FBD)

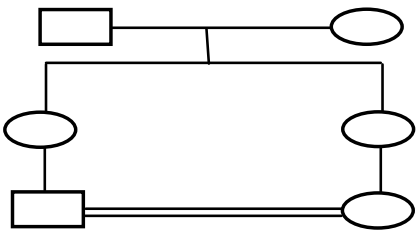

Type II (MZD)

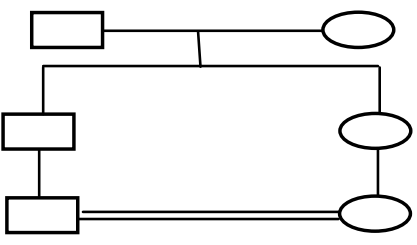

Type III(FZD)

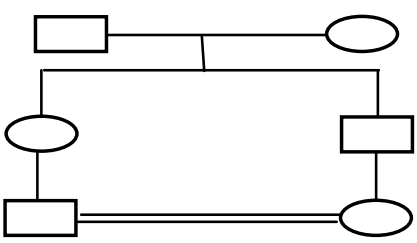

Type IV (MBD)

Fig.3. Types of First Cousin Marriages

FBD: Father's Brother's Daughter, MZD: Mother's Sister's Daughter, FZD: Father's Sister's Daughter MBD: Mother's Brother's Daughter MEN

WOMEN

The coefficient of consanguinity was estimated by the calculation of the mean inbreeding coefficient according to the formula:

$$
\alpha=\sum_{i} f_{i} F_{I}
$$

Where $f i$ is the relative frequency of pairs in each category of consanguineous marriageand FI is the coefficient of consanguinity of this category [10].

\subsection{Methodology}

A prospective study was conducted among a randomly selected sample of 160 university students in Tanger in the region of Tanger Tetouan of Morocco in 2014. All students were interviewed using a structured questionnaire.The data were seized on Excel and the statistical analysis was made by statistical logiciel. The statistical methodology was based on the descriptive analysis of the data and was expressed in number and in 
frequency for the qualitative variables. For the analytical statistics, the qualitative variables were compared by the test Khi2 ( $\chi 2)$.

\section{Resultats}

Table 1. Consanguinity rate among the population of the TangerTetouan region

\begin{tabular}{lcccc}
\hline \multirow{2}{*}{ Geneartions } & Currentgeneration & \multicolumn{2}{c}{ Previousgeneration } & $p$ value \\
\cline { 3 - 4 } & & Parents paternels & Parents maternels & \\
\hline consanguineous marriages & $63(39,4 \%)$ & $20(12,5 \%)$ & $17(10,6 \%)$ & $\chi^{2}=p<0,001$ \\
Non-consanguineous marriages & $97(60,6 \%)$ & $140(87,5 \%)$ & $143(89,4 \%)$ & \\
\hline
\end{tabular}

The study of the profile of the consanguineous marriages in the region of Tanger-Tetouan, according to the table 1, revealed a highly significant difference in the rates of the consanguineous marriages betweenthe current and previous generation.It was $39,4 \%$ in the current generation compared to $11,5 \%$ for the previous generation, $\mathrm{p}<0,001(12,5 \%$ of the paternal generation and $10,6 \%$ for the maternal parents), with a mean inbreeding coefficient (up to second cousins) of $0,02033$.

Table 2. Current and previous generation marriage profile in the region Tanger-Tetouan, Morocco

Type of mariage

Currentgeneration $\quad$ Previousgeneration $p$ value

\begin{tabular}{|c|c|c|c|c|c|}
\hline \multicolumn{2}{|l|}{ 1уре от martage } & \multirow{3}{*}{\multicolumn{2}{|c|}{$\begin{array}{cc}\text { Parents } & \text { Paternal parents } \\
\mathrm{n}(\%) & \mathrm{n}(\%)\end{array}$}} & \multirow{3}{*}{$\begin{array}{c}\text { Maternal parents } \\
\mathrm{n}(\%)\end{array}$} & \multirow[b]{3}{*}{$\chi^{2}=\mathrm{p}<0,001$} \\
\hline & & & & & \\
\hline & & & & & \\
\hline \multirow[t]{4}{*}{ First cousins } & $F B D$ & & & & \\
\hline & $M Z D$ & & & & \\
\hline & $F Z D$ & $48(76,2)$ & $11(55,0)$ & $9(52,9)$ & \\
\hline & $M B D$ & & & & \\
\hline \multirow{3}{*}{$\begin{array}{l}\text { Othertypical of } \\
\text { The cons } \\
\text { marriage }\end{array}$} & First cousin once removed & $7(11,1)$ & - & - & \\
\hline & Second cousin & $2(3,2)$ & $1(5,00)$ & - & \\
\hline & Total & $9(14,3)$ & $1(5,00)$ & - & \\
\hline \multirow{3}{*}{\multicolumn{2}{|c|}{$\begin{array}{l}\text { Consanguinity of distant relatives } \\
\text { Ensemble of consanguineous marriage } \\
\text { Inbreeding Coefficient }\end{array}$}} & $6(9,5)$ & $8(40,0)$ & $8(47,1)$ & \\
\hline & & $63(100)$ & $20(100)$ & $17(100)$ & \\
\hline & & 3,25 & 0,703125 & 0,5625 & \\
\hline
\end{tabular}

The study showed that in the whole of the consanguineous marriages, tended towards the marriages between first cousins in current generation, the rate was $76,2 \%$ against $53,9 \%$ to the previous generation, this difference is highly significant, $\mathrm{P}<0,001$. While $14,3 \%$ were other types of consanguineous marriage, with 11 , $1 \%$ for the first cousin once removed and

$3,2 \%$ for second cousin.

To the generation of the paternal grandparents, more than half of consanguineous marriages were between first cousins, whereas $40 \%$ of unions were ofdistant relatives.

As for the generation of the maternal grandparents, $52,9 \%$ of the related marriages were between first cousins against $47,1 \%$ of marriage distant relatives.

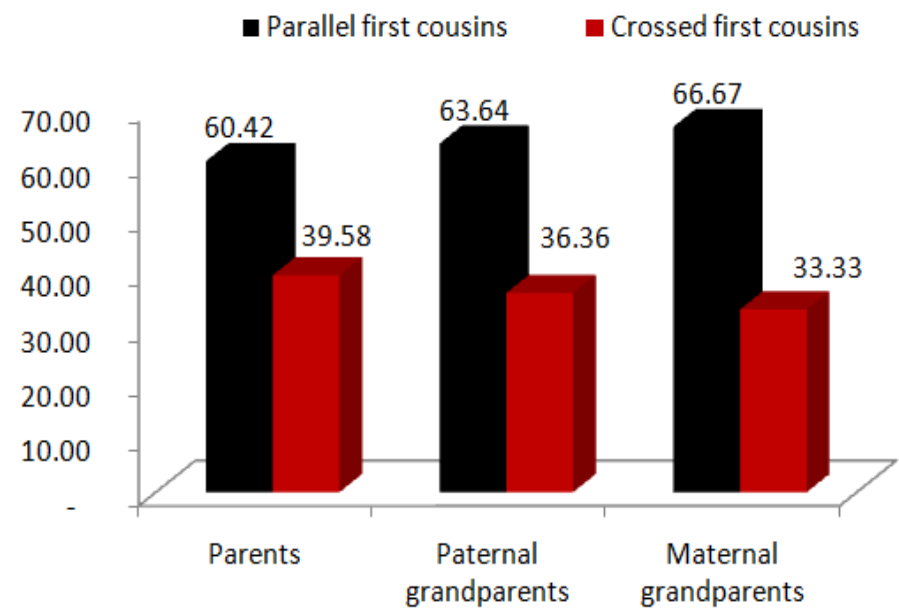

Fig.4. Marriage rate of first cousins in the Tanger-Tetouan region 
The distribution of the marriages between first cousins through the generations, showed that the frequency of unions between parallel cousins was superior thanthat of the unions between crossed cousins (Figure4). It was 60, $42 \%$ against $39,58 \%$ respectively to the current generation.

While at the maternal parents was $66,67 \%$ against $33,33 \%$ and $63,64 \%$ against $36,36 \%$ at the paternal parents. The difference was not statically significant between both types of the alliances $(P>0,05)$.

It is necessary to indicate that the frequency of the marriages between parallel and crossed cousins knew relatively certain stability along the studied generations. $60,42 \%$ of the marriage between parallel cousins at the spouses and 66,67\%; 63,64 \% respectively at the maternal and paternal parents. While frequency of unions between crossed cousin's registered $39,58 \%$ to the current generation and that of the maternal and paternal parents was $33,33 \%$ and $36,36 \%$ respectively.

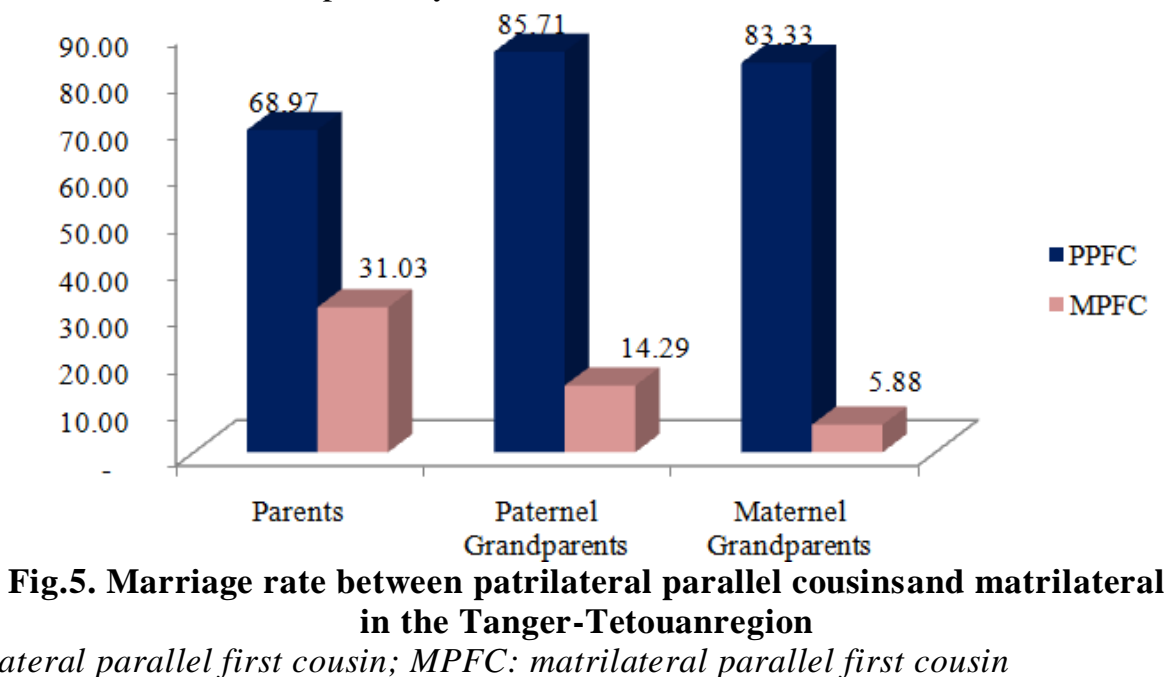

PPFC: patrilateral parallel first cousin; MPFC: matrilateral parallel first cousin

Among the parallel first cousins, the marriage with thedaughter of brother of the father (patrilateral parallel)was the most answered that with the daughter of sister of mother (matrilateral parallel)to both studied generations. The rate was $68,97 \%$ against $31,03 \%$ to the generation of the parents, then, it was $85,71 \%$ against $14,29 \%$ and $83,33 \%$ against 5,88\% to the generation of the paternal and maternal parents, respectively (Figure 5). Nevertheless, it is necessary to note that there was a regression of the marriages withthedaughter of brother of the father, for the benefit of the alliances with the daughter of sister of motherthrough the generations.

\section{Discussion}

The consanguineous marriage in the region of Tanger-Tetouan stays a current practice; it represents $39,4 \%$ of the cases compared to with other regions of Morocco with respectively $22,8 \%$ in the region Gharb Chrarda Beni Hsen and 20,6\% in the region of de Rabat-Salé-Zemmour-Zaer[11,12].

Other studies to the population of Fritissa in the Middle Atlas of Morocco and in the region of Doukkala registered respectively $30,32 \%$ and 26,06 of the consanguineous marriages[13].

This high tendency is concomitant with other Arab-Muslim countries which showed another increase of the consanguineous marriages as Saudi Arabia (58 \%)[14], Jordan (51\%) [15], United ArabEmirates (50,5 $\%$ ) [16], Kuwait (54 \%) [17], Qatar (54, $5 \%$ ) [18],Yemen (40 \%) [19] and Bahrain[20].

This preferencewasalsoregistered in Asian countries as India and Pakistan where the consanguineous marriage affected $22 \% \%$ and $60 \%[21,22]$.

Unlike, on an international scale, in particular in South America and Europe, the rate of the consanguinityremainslower in correlationwith the Arab-Muslim and Asian countries.The consanguinity in Brazil and in Chile wasalsorespectively 20,19\% and 14,9\% [23,24]. Whileat the level of Spain the rate of the consanguineous marriage establishconstitutedonly $5,70 \%$ [25].

Our studyalsorevealed a growth of the consanguineousmarriages to the currentgeneration $(39,4 \%)$ against $11,55 \%$ to the previous one (12,5\% of the paternalgeneration and $10,6 \%$ for the maternal parents).

Manyfactorscouldexplainthis important frequency of the consanguineous marriage in the region of Tanger-Tetouan, to know the valuation of thismarriage type in thecontextthe traditions worried of maintaining the familycohesion, or the protection of the heritage and youngage of the spouseswho urge the parents to choose the future partner of theirchildren[26;27]. Indeed, according to the data of the National Survey on the Family of 1995, $16 \%$ onlymarriagesresultfrom a mutualchoicebetweenbothspouses. The parents and the family put pressure on the personoldenough to getmarried, in particularduring the first 
marriage[28].Otherstudiesreportedthat the spouses of rural originfavor the consanguineous marriage thatthose of originurban[29].

In contrast, the technology, the materiallevel and the modernization have no influence on the choice of the future spouseconcerning the Arab-Muslim society such as the countries of the Middle East, Of the North of AfricaincludedMorocco, thisis a part of their traditions. On the other hand, industrialized countries not are a member of thistendency.

The increaseregistered by the consanguineousmarriages to the currentgenerationwasalsoaccompanied in a strongtendency, towards unions between first cousins (76,2 \%) against 14,28\% amongthe distant relatives.Indeedourstudyrevealedthatthereis a clearregression of the marriagesbetween distant relatives for the benefit of the first cousins throughbothstudiedgenerations.Moreover, a surveyat the level of Moroccoshowedthat the reduction in the endogamyisexplainedby the regression of the marriageswith distant relatives.Indeed, the rate of the endogamywith a first cousin remainedalmost stable between 1995 and $2010(16,3 \%$ and 15,5\% respectively), whilethatwith a distant relatives knew a reduction sensitive from $13 \%$ to $5,1 \%$ whence the progress of the marriageswith a $56 \%$ first cousin in 1995 a75 \% in 2010 [8].

This remainssimilar for the MuslimArab countries where the third of the marriageswasbetween first cousin [30].In the Yemen more than $85 \%$ of the consanguineousmarriageswasbetween first cousins [31]. In Tunisia and in Pakistan reportedrespectively 70,13\% and $69 \%$ of union between first cousins [32,33].

It shouldbenotedthat the type of marriage has not been reported in approximately $50 \%$ of the previousgenerationcompared to the currentgeneration $(9,52 \%)$, seenthat the studentsquestionedduring the survey ignore the type of consanguinitybetweentheirpaternal and maternalgrandparents, whatrequiresdeepened investigations.

Our studyshowedthatbothstudiedgenerationsgrant a preference for unions betweenparallel first cousins that the crossed cousins, in particularwith the daughter of brother of the father $(68,97 \%)$. This remains comparable with a studycarried out in India[34], anddifferentwith the Israeliresults[35].It couldbeconnected to social and cultural faithsprofoundlyrooted in our country as the economicinterest, the right and the duty of the cousin to marryhis cousin.

Nevertheless, weregistered in ourstudy a regression of the marriagesbetweenpatrilaterals cousins in favour of matrilaterals. Such situation wasinterpreted by Khlat in herstudy in the Lebanon as a drift matrilatral of the system of kinship,whichhad the impact of the economicdevelopment on the status of the woman in the country, where the sexualroles are important in the social organization[36].

\section{CONCLUSION}

The frequency of consanguineous marriage among the currentgenerationis important, couldbeconsidered a common tradition and rooted in the region of Tangier-Tetouan Morocco. A study on the main trends of consanguineous marriages in this population remainsdesirable, therebydeepening the design and understanding of the determinants of this practice factors.

\section{Remerciements}

This study joins in a frame of a doctoral search.Wewouldlike to thank Pr, Ahmed AARAB (Faculty of Science and Technique, Tanger, Morocco), Pr,BelkacemGharrab (Larache, Morocco) for their support in the fulfillment of thiswork. Wethanksincerely all thosewhohelped us by far or closely.

\section{References}

[1] S. Al-Arrayed, and H.Hamamy, "The changing profile of consanguinity rates in Bahrain, 1990-2009," J BiosocSci, vol. 44, no. 3, pp. 313-9, 2012

[2] H.Hamamy, and Med. Genet, "Consanguineous marriages, pearls and perils: Geneva International Consanguinity," Workshop Report, vol.13, no.9, pp. 841-7, 2011

[3] L. Ben M'rad, and N. Chalbi, “Le choix matrimonial en Tunisie est-il transmissible?,” Antropo, vol. 7, pp. 31-37, 2004.

[4] Ministère de la Santé Publique, Maroc, "Enquête Nationale sur la Planification Familiale, la Fécondité et la Santé de la Population au Maroc," ENPS-I 1987, Rabat, Maroc, 1989.

[5] Ministère de la Santé Publique, Maroc, “Enquête Nationale sur la Santé de la Mère et del'Enfant," ENSME 1997, Pan Arab Project for Child Development PAPCHILD, League of Arab States,"2011.

[6] E. Freundlich, and N.Hino, “Consanguineous marriage among rural Arabs in Israel,” Isr J Med Sci, vol. 20, no. 11, pp. 1035-8, 1984.

[7] A. hahid, S. Saeed, and S.Mahmood, "Familyhistory of diabetes and parental consanguinity: important risk for impairedfasting glucose in southeastAsians," West Indian Med J, vol. 61, no. 3, pp. 219-23, 2012.

[8] Haut-Commissariat au plan (Maroc), Recensement général de la population et de l'habitat de 2010. Caractéristiques démographiques et socio-économiques : région de Tanger-Tétouan, 2010.

[9] S. Denic, "EnquêteNationalesur la Santé de la Mèreet del'Enfant," Consanguinity as risk factor for cervical carcinoma," Med Hypotheses, vol. 60, no. 3, pp. 321-4, 2003.

[10] A. Jacquard, and F. Reynes, "Mesuredémographique de fardeaugénétique," Population, vol. 4, pp. 625-648, 1968.

[11] H. Hami, A. Soulaymani, and A.Mokhtari, "Endogamie, Isonymie et Consanguinité dans la région du Gharb Chrarda Béni Hsen (Maroc)," Antropo, vol. 11, pp. 223-233, 2006 
[12] H. Hami, A. Soulaymani, and A.Mokhtari, "Les Déterminants des Mariages Consanguins dans la Région de Rabat-Salé-ZemmourZaer (Maroc)," Antropo, vol. 18, pp. 27-35, 2009.

[13] M.Latifi, L. Sbii, and H. Hami, "Le Choix du conjoint dans la région de Fritissa (Est du Maroc)," Antropo, vol. 23, pp. 99107,2010 .

[14] MA. el-Hazmi, AR. al-Swailem, and R. Sulaimani, “Consanguinityamong the SaudiArabianpopulation,”J Med Genet, vol. 32, no. 8, pp. 623-6,1995.

[15] H. Hamamy, L. Jamhawi and J. Al-Darawsheh, "Consanguineous marriages in Jordan: whyis the rate changingwith time?," Clin Genet, vol. 67, no. 6, pp. 511-6, 2005.

[16] LI. Al-Gazali, A.Bener, and YM. Abdulrazzaq, "Consanguineous marriages in the United ArabEmirates,"J BiosocSci, vol. 29, no. 4, pp. 491-7, 1997.

[17] SA. Al-Awadi, MA. Moussa, and KK. Naguib, "Consanguinityamong the Kuwaiti population," Clin Genet, vol. 27, no. 5, pp. 483-6, 1985.

[18] A. Bener, and KA.Alali, “Consanguineous marriage in a newlydeveloped country: the Qatari population,” J BiosocSci, vol. 38, no. 2, pp. 239-46, 2006

[19] R.Jurdi, and PC. Saxena,“ The prevalence and correlates of consanguineous marriages in Yemen: similarities and contrastswithotherArab countries," J BiosocSci, vol. 35, no. 1, pp. 1-13, 2003.

[20] S. Al-Arrayed, and H. Hamamy, "The changing profile of consanguinity rates in Bahrain, 1990-2009," J BiosocSci, vol. 44, no. 3, pp. 313-9, 2012.

[21] R. Hussain, and AH.Bittles, "Sociodemographiccorrelates of consanguineous marriage in the Muslim population of India," J BiosocSci, vol. 32, no. 4, pp. 433-42, 2000.

[22] W.Qidwai, "Prevalence and perceptions about consanguineous marriagesamong patients presenting to familyphysicians, in 2001 at a TeachingHospital in Karachi, Pakistan," Asia Pacific FamilyMedicine, vol. 2, pp. 27-31, 2003.

[23] M.Weller, M. Tanieri and JC. Pereira, "Consanguineous unions and the burden of disability: a population-basedstudy in communities of NortheasternBrazil," Am J Hum Biol, vol. 24, no. 6, pp. 835-40, 2012.

[24] P. Villanueva, MA. Fernández and Z. De Barbieri, "CONSANGUINITY ON ROBINSON CRUSOE ISLAND, AN ISOLATED CHILEAN POPULATION," J BiosocSci, vol. 46, no. 4, pp. 546-55, 2014.

[25] TA. Varela, RL.Aínsua, and J.Fariña, "Evolution of consanguinity in the Bishopric of Lugo (Spain) from 1900 to 1979," Ann Hum Biol, vol. 28, no. 5, pp. 575-88, 2001 .

[26] OM. Alper, H.Erengin and AE.Manguoğlu, "Consanguineous marriages in the province of Antalya, Turkey," Ann Genet, vol. 47, no. 2, pp. 129-38, 2004.

[27] MM.Sirdah, "Consanguinity profile in the Gaza Strip of Palestine: large-scalecommunity-basedstudy," Eur J Med Genet, vol. 57, no. 2-3, pp. 90-4, 2014.

[28] Direction de la Statistique, Maroc, Enquête Nationale sur la Famille ENF 1995, Rabat, Maroc.

[29] AH. Bittles, R. Hussain and YM.Abdulrazzaq, "An analysis of consanguineous marriage in the Muslim population of Indiaatregional and state levels, ” Ann Hum Biol, vol. 27, no. 2, pp. 163-71, 2000.

[30] AA. Gunaid, NA. Hummad and KA.Tamim, "Consanguineous marriage in the capital city Sana'a, Yemen,"J BiosocSci, vol. 36, no. 1, pp. 111-21, 2004.

[31] R. Jurdi, andPC.Saxena, “ The prevalence and correlates of consanguineous marriages in Yemen: similarities and contrastswithotherArab countries," J BiosocSci, vol. 35, no. 1, pp. 1-13, 2007.

[32] E. Kerkeni, K.Monastiri and B.Saket, " Interplay of socio-economicfactors, consanguinity, fertility, and offspringmortality in Monastir, Tunisia," Croat Med J, vol. 48, no. 5, pp. 701-7, 2007.

[33] W.Qidwai, "Prevalence and perceptions about consanguineous marriagesamong patients presenting to familyphysicians, in 2001 at a TeachingHospital in Karachi, Pakistan,” Asia Pacific FamilyMedicine, vol. 2, pp. 27-31, 2003.

[34] AH.Bittles, and R. Hussain and YM.Abdulrazzaq, "An analysis of consanguineous marriage in the Muslim population of Indiaatregional and state levels, ” Ann Hum Biol, vol. 27, no. 2, pp. 163-71, 2000.

[35] L. Jaber, GJ. Halpern and T.Shohat, "Trends in the frequencies of consanguineous marriages in the IsraeliArabcommunity, "Clin Genet, vol. 58, no. 2, pp. 106-10, 2000.

[36] M. Khlat, "Consanguineous marriages in Beirut: Time trends, spatial distribution," Biodemography and Social Biology, vol. 35, no. 3- 4 pp. 324-330, 1988 . 